\title{
Association Analyses of SNAP25, HNMT, FCHSDI, and DBH Single-Nucleotide Polymorphisms with Parkinson's Disease in a Northern Chinese Population
}

\section{Cuiyun Dai \\ Yichi Zhang \\ Xiaoni Zhan \\ Meihui Tian \\ Hao Pang}

Department of Forensic Genetics and Biology, School of Forensic Medicine, China Medical University, Shenyang, I I0I22, People's Republic of China
Correspondence: Hao Pang

Tel +86-24-31939435

Email hpang@cmu.edu.cn
Purpose: Sequencing potentially causal and susceptible genes and genome-wide association studies in samples from Parkinson's disease (PD) patients has revealed several related loci. The genes for synaptosome-associated protein of $25 \mathrm{kDa}$ (SNAP25), histamineN-methyltransferase (HNMT), FCH and double SH3 domains 1 (FCHSD1) and dopamine $\beta$ hydroxylase $(\mathrm{DBH})$ are candidate loci and have not been studied in a northern Chinese population. We explored the genetic distribution of four single-nucleotide polymorphisms (rs3746544, rs11558538, rs456998, rs129882) located on SNAP25, HNMT, FCHSD1 and $\mathrm{DBH}$, respectively.

Patients and Methods: A total of 330 patients with sporadic PD and 332 healthy controls (HCs) were recruited from a northern Chinese population. Polymerase chain reaction restriction fragment length polymorphism was used to genotype these four SNPs.

Results: After statistical analyses and correction of the genotyping results, the mutant-allele $\mathrm{T}$ in rs456998 of FCHSD1 was found to be significantly related to reducing the PD risk $(P=$ $0.029, \mathrm{OR}=0.754,95 \% \mathrm{CI}=0.586-0.971$, power $=0.591)$. However, rs3746544, rs11558538, and rs129882 did not show an association with PD.

Conclusion: FCHSD1 rs456998 may have a protective role in PD in a northern Chinese population, but more studies are needed to support this suggestion.

Keywords: Parkinson's disease, single nucleotide polymorphism, SNAP25, HNMT, FCHSD1, DBH, association study

\section{Introduction}

Parkinson's disease (PD) is a neurological disease. It is characterized mainly by degeneration of dopaminergic neurons and noradrenergic neurons, and deposition of Lewy bodies in surviving neurons. Researchers have found that PD is related to genetics, ethnicity, geographical variation, tobacco smoking, pesticide exposure, fat, and other risk factors. ${ }^{1-3}$ PD pathogenesis is incompletely understood. However, numerous studies have shown that PD is associated with toxic dysregulation of $\alpha$ synuclein, mitochondrial dysfunction, and oxidative stress. ${ }^{4-6}$ Complex interactions between genetic and environmental factors are believed to contribute to the development of PD. ${ }^{7}$ Many causal and susceptible loci were found and duplicated based on GWAS. However, simple genetic factors may cause PD (or be associated with PD) and a genetic contribution to PD onset has been established. 
There were a large number of studies aimed at finding accurate association between PD and genes in different populations. Nevertheless, most PD cases are sporadic. In particular, the predominant sporadic variant of PD seems to be associated with a combination of common variants within several genes. In addition, like many geneticsrelated diseases, genome-wide association studies (GWAS) on PD have been extensive. Increasing numbers of studies have highlighted a clear genetic contribution among PD patients. Several causal loci and susceptible loci have been found and duplicated in different ethnicities and populations based on GWAS and the function of individual genes.

Studies on the level of synaptosome-associated protein of $25 \mathrm{kDa}$ (SNAP25) in the presynaptic plasma membrane have demonstrated synaptic dysfunction to be an initial event of the subsequent neurodegeneration in several neurodegenerative diseases of the central nervous system. Also, SNAP25 polymorphisms have been associated with distinct neuropsychiatric and neurological disorders, such as $\mathrm{PD}^{8}$ Histamine-N-methyltransferase (HNMT) can degrade the small-molecule neurotransmitter histamine, and a common genetic polymorphism in exon 4 of HNMT is associated with PD. ${ }^{9,10} \mathrm{FCH}$ and double SH3 domains 1 (FCHSD1) is predicted to function in actin dynamics. Fernandez-Santiago et al showed that rs456998 of FCHSD1 combined with rs8111699 of serine/threonine kinase 11 (STK11), rs1732170 of glycogen synthase kinase 3 beta (GSK3B), and rs356219 of synuclein alpha (SNCA) genes were related to PD in a Spanish population. ${ }^{11}$ Dopamine (DA) in synaptic vesicles is converted to norepinephrine (NE) by the enzyme dopamine $\beta$ hydroxylase (DBH). A GWAS of PD-sibling pairs among a UK population revealed linkage to the chromosomal location 9q, which overlaps with the $D B H$ locus. ${ }^{12}$ Moreover, Ghosh et al proposed that $D B H$ is a modifier gene of PD in a study in an eastern Indian population. ${ }^{13}$

In recent years, we have published the results of association analyses with PD in northern China based on the candidate genes and GWAS of PD. ${ }^{14-17}$ However, accurate research on the correlation between these four gene loci (SNAP25, HNMT, FCHSD1, and DBH) and PD in China is lacking. Several studies have aimed to find an accurate association between PD and genes in different populations. Furthermore, thorough understanding of the genetic architecture of the common, complex forms of PD in northern China and data accumulation are rational and important aims.
We analyzed the single-nucleotide polymorphisms (SNPs) on SNAP25, HNMT, FCHSD1, and DBH genes in a cohort of Chinese patients with sporadic PD to ascertain their possible involvement in PD.

\section{Patients and Methods Ethical Approval of the Study Protocol}

This study was conducted in accordance with the Helsinki Declaration, and was approved by the Ethics Association of China Medical University (Shenyang, China). Participants provided written informed consent.

\section{Study Cohort}

A total of 330 PD patients (164 males and 166 females) and 332 healthy controls (HCs; 193 males and 139 females) from northern China were recruited randomly. The age at enrollment of PD patients was $62.42 \pm 9.59$ years, and the age at PD onset was $60.98 \pm 10.23$ years. The age at enrollment of the HC group was $68.95 \pm 13.97$ years. Patients were diagnosed with idiopathic PD by a very experienced neurologist at the First Affiliated Hospital of China Medical University. Patients met the diagnostic criteria for $\mathrm{PD}$ set by the British Brain Bank. ${ }^{18}$ HCs did not have a neurodegenerative disease.

\section{Genotyping}

Samples of peripheral blood were collected from all participants. Genomic DNA was extracted using the sodium dodecyl sulfate-protease K-phenol-chloroform method. According to published sequences in GenBank, we designed forward primers and reverse (Table S1). We synthetically generated a Xho I restriction endonuclease site in the amplified product of the rs3746544 locus using a mismatched polymerase chain reaction (PCR) primer based on published sequences. The products of PCR amplification and enzyme digestion were verified by sequencing.

Polymerase chain reaction-restriction fragment length polymorphism (PCR-RFLP) was used to identify SNPs. The PCR system (in a final volume of $10 \mu \mathrm{L}$ ) consisted of $5 \mu \mathrm{L}$ of $2 \times$ DreamTaq $^{\circledR}$ Green Master Mix (Thermo Scientific, Waltham, MA, USA), $10 \mathrm{ng}$ of genomic DNA, $0.2 \mu \mathrm{M}$ of forward primer, and $0.2 \mu \mathrm{M}$ of reverse primer (Genewiz, Tianjin, China). For rs3746544 and rs129882, PCR amplification was done with an initial denaturation step at $94^{\circ} \mathrm{C}$ for $5 \mathrm{~min}$, followed by 30 cycles of denaturation at $94^{\circ} \mathrm{C}$ for $30 \mathrm{~s}$, annealing at $60^{\circ} \mathrm{C}$ for 30 
$\mathrm{s}$, extension at $72^{\circ} \mathrm{C}$ for $30 \mathrm{~s}$, and an eventual elongation at $72^{\circ} \mathrm{C}$ for $4 \mathrm{~min}$. For rs 456998 and rs 11558538 , PCR amplification was undertaken with annealing at $62^{\circ} \mathrm{C}$ for $30 \mathrm{~s}$, and the other steps were the same as those for the loci stated above. The PCR products of rs 3746544 on SNAP25, rs11558538 on HNMT, and rs129882 on DBH were digested at $37^{\circ} \mathrm{C}$ for $1 \mathrm{~h}$ in $10 \mu \mathrm{L}$ of $\mathrm{H}$ buffer containing $2 \mu \mathrm{L}$ of PCR product, $1 \mu \mathrm{L}$ of $10 \times \mathrm{H}$ buffer, $6.75 \mu \mathrm{L}$ of double-distilled $\mathrm{H}_{2} \mathrm{O}$, and $0.25 \mu \mathrm{L}$ of restriction enzymes (Xho I, EcoR V, Sph I), all of which were from TaKaRa Biotechnology (Shiga, Japan). The PCR product of rs 456998 on FCHSDl was digested at $37^{\circ} \mathrm{C}$ for $1 \mathrm{~h}$ in $10 \mu \mathrm{L}$ of $\mathrm{T}$ buffer containing $2 \mu \mathrm{L}$ of PCR product, $1 \mu \mathrm{L}$ of $10 \times \mathrm{T}$ buffer, $1 \mu \mathrm{L}$ of bovine serum albumin $(0.1 \%), 5.75 \mu \mathrm{L}$ of double-distilled $\mathrm{H}_{2} \mathrm{O}$, and $0.25 \mu \mathrm{L}$ of $A f a \mathrm{I}$, all of which were from TaKaRa Biotechnology. The enzyme-digested products of rs129882 and rs11558538 were separated on $1 \%$ agarose gel. The enzyme-digested products of rs 3746544 and rs456998 were isolated on $2 \%$ agarose gel. Then, fragments were viewed on a gel-imaging system (Tanon 2500R, Shanghai, China).

For rs3746544 of $S N A P 25$, the PCR products of length $225 \mathrm{bp}$ (which represent the undigested mutant-type allele T) were digested into 205-bp and 20-bp fragments (which represent the digested wild-type allele $G$ ). The loci of other SNPs were genotyped in the same manner. For rs11558538 of HNMT, PCR products of length $307 \mathrm{bp}$ (which represent the undigested wild-type allele $\mathrm{C}$ ) were digested into 259-bp and 48-bp fragments (which represent the mutant-type allele T). For rs456998 of FCHSD1, PCR products of length $195 \mathrm{bp}$ (which represent the undigested mutant-type allele T) were digested into 128-bp and 67-bp fragments (which represent the wild-type allele G). For rs 129882 of $D B H$, PCR products of length $517 \mathrm{bp}$ (which represent the undigested wild-type allele $\mathrm{C}$ ) were digested into 369-bp and 148-bp fragments (which represent the mutant-type allele T).

\section{Statistical Analyses}

First, the Hardy-Weinberg equilibrium was tested in samples from the PD patients and HCs. Then, the results were analyzed by SPSS 20.0 (IBM, Armonk, NY, USA) and PS 3.1.6 (Power and Sample Size Calculations; https://biostat. app.vumc.org/wiki/Main/PowerSampleSize/). Multiple comparisons necessitated application of the Bonferroni correction $(\alpha=0.05 / 4=0.0125) . P \leq 0.05$ (two-sided) was considered significant.

\section{Results}

\section{Genetic Parameters and Association} Analyses

The Hardy-Weinberg equilibrium was tested on samples from the PD group and $\mathrm{HC}$ group. The $P$-value for rs3746544, rs11558538, rs456998, and rs129882 in the PD group was $0.6262,0.0944,0.2247$, and 0.3507, whereas it was $0.0605,0.4399,0.6551$, and 0.1824 , respectively, in the $\mathrm{HC}$ group. The allelic and genotypic frequencies of the PD group and $\mathrm{HC}$ group, as well as the allelic and genotypic frequencies of rs456998 based on sex, are shown in Table 1. The frequency of rs 456998 on FCHSD1 was significantly different between the PD group and $\mathrm{HC}$ group. The $\mathrm{T}$ allele in the PD group $(P=0.029$, odds ratio $(\mathrm{OR})=0.754,95 \%$ confidence interval $(\mathrm{CI})=$ $0.586-0.971$, power $=0.591)$ was less frequent than that in the HC group. However, other SNPs showed no significant association between the $\mathrm{PD}$ group and $\mathrm{HC}$ group (rs3746544: $P=0.07, \mathrm{OR}=0.796,95 \% \mathrm{CI}=0.622-1.018$, power $=0.443 ;$ rs11558538: $0.687,1.123,0.660-1.911$, 0.071; rs129882: $0.773,1.037,0.827-1.299,0.061$ ). Then, we investigated the sex differences of rs456998 (Table 1) between PD patients and HCs, but there was no obvious difference (males: $P=0.066, \mathrm{OR}=0.713,95 \%$ $\mathrm{CI}=0.504-1.009$, power $=0.481$; females: $0.294,0.806$, $0.555-1.171,0.206$ ).

\section{Genotype Distributions of rs456998 Between PD Patients and HCs Based on Four Genetic Models}

There was no significant difference between the PD group and $\mathrm{HC}$ group based on a homozygous co-dominant model $(P=0.411, \mathrm{OR}=0.738,95 \% \mathrm{CI}=0.387-1.409$, power $=$ $0.259)$, heterozygous co-dominant model $(0.017,0.669$, $0.483-0.926,0.942)$, dominant model $(0.015,0.679$, 0 .$498-0.925,0.935)$ and recessive model $(0.748,0.861,0$. $457-1.622,0.108)$ after application of the Bonferroni correction $(\alpha=0.05 / 4=0.0125)$ (Table 2$)$.

\section{Discussion}

PD is the second most common progressive neurodegenerative disorder (after Alzheimer's disease). ${ }^{19}$ Several studies have attempted to reveal the relationship between genes and PD. A wealth of loci of candidate genes have been found to be associated with PD, and this connection has been confirmed in different populations. However, 
Table I Distribution of Allelic and Genotypic Frequencies in Four Investigated SNPs and One of rs456998 Based on Sex

\begin{tabular}{|c|c|c|c|c|c|c|}
\hline SNPs & Types & PD (\%) & Control (\%) & OR (95\% CI) & p value & Power \\
\hline rs3746544 & $\begin{array}{l}\text { T } \\
\text { GG } \\
\text { GT } \\
\text { TT }\end{array}$ & $\begin{array}{c}474(71.820) \\
28(8.480) \\
130(39.390) \\
172(52.120)\end{array}$ & $\begin{array}{c}506(76.200) \\
25(7.530) \\
108(32.530) \\
199(59.940)\end{array}$ & $\begin{array}{c}0.796(0.622-1.018) \\
\text { NA }\end{array}$ & $\begin{array}{l}0.07 \\
0.126\end{array}$ & $\begin{array}{l}0.443 \\
\mathrm{NA}\end{array}$ \\
\hline rsII558538 & $\begin{array}{l}\mathrm{T} \\
\mathrm{CC} \\
\mathrm{CT} \\
\mathrm{TT}\end{array}$ & $\begin{array}{c}30(4.550) \\
302(91.520) \\
26(7.880) \\
2(0.600)\end{array}$ & $\begin{array}{c}27(4.070) \\
305(91.870) \\
27(8.130) \\
0\end{array}$ & $\begin{array}{c}1.123(0.660-1.911) \\
\text { NA }\end{array}$ & $\begin{array}{c}0.687 \\
0.569 \\
\text { (corrected) }\end{array}$ & $\begin{array}{l}0.07 I \\
\text { NA }\end{array}$ \\
\hline rs456998 & $\begin{array}{l}\text { T } \\
\text { GG } \\
\text { GT } \\
\text { TT }\end{array}$ & $\begin{array}{l}142(21.520) \\
207(62.730) \\
104(31.520) \\
19(5.750)\end{array}$ & $\begin{array}{c}\text { I } 77(26.660) \\
\text { I } 77(53.310) \\
\text { I } 33(40.060) \\
22(6.630)\end{array}$ & $\begin{array}{c}0.754(0.586-0.97 I) \\
\text { NA }\end{array}$ & $\begin{array}{l}0.029 \\
0.046\end{array}$ & $\begin{array}{l}0.591 \\
\mathrm{NA}\end{array}$ \\
\hline Male & $\begin{array}{c}\text { T } \\
\text { Number } \\
\text { GG } \\
\text { GT } \\
\text { TT } \\
\text { Number }\end{array}$ & $\begin{array}{c}69 \\
328 \\
103 \\
53 \\
8 \\
164\end{array}$ & $\begin{array}{c}105(0.272) \\
386 \\
104 \\
73 \\
16 \\
193\end{array}$ & $\begin{array}{c}0.7 \mid 3(0.504-1.009) \\
\text { NA }\end{array}$ & 0.066 & $0.48 \mathrm{I}$ \\
\hline Female & $\begin{array}{c}\text { T } \\
\text { Number } \\
\text { GG } \\
\text { GT } \\
\text { TT } \\
\text { Number }\end{array}$ & $\begin{array}{c}73 \\
332 \\
104 \\
51 \\
11 \\
166\end{array}$ & $\begin{array}{c}72(0.259) \\
278 \\
73 \\
60 \\
6 \\
139\end{array}$ & $\begin{array}{c}0.806(0.555-|.| 7 \mid) \\
\text { NA }\end{array}$ & 0.074 & NA \\
\hline rsI29882 & $\begin{array}{l}\mathrm{T} \\
\mathrm{CC} \\
\mathrm{CT} \\
\mathrm{TT}\end{array}$ & $\begin{array}{l}233(35.300) \\
142(43.030) \\
143(43.330) \\
45(13.640)\end{array}$ & $\begin{array}{l}229(34.490) \\
137(41.270) \\
161(48.490) \\
34(10.240)\end{array}$ & $\begin{array}{c}1.037(0.827-1.299) \\
\text { NA }\end{array}$ & $\begin{array}{l}0.773 \\
0.259\end{array}$ & $\begin{array}{l}0.061 \\
\text { NA }\end{array}$ \\
\hline
\end{tabular}

Note: Total PD and control numbers are 330 and 332, respectively.

Table 2 Analysis Under Different Genetic Models for rs456998 Locus

\begin{tabular}{|l|c|c|c|c|c|c|}
\hline Genetic Model & Types & PD & Control & P value & OR (95\% CI) & Power \\
\hline Homozygous & TT & 19 & $22(0.11 \mathrm{I})$ & $0.4 I I$ & 0.738 & 0.259 \\
Co-dominant & GG & 207 & 177 & & $(0.387-1.409)$ & 0.669 \\
Heterozygous & GT & 104 & 133 & 0.017 & $(0.483-0.926)$ & 0.942 \\
Co-dominant & GG & 207 & 177 & & 0.679 & 0.935 \\
Dominant & GG & 207 & 177 & 0.015 & $(0.498-0.925)$ & 0.861 \\
& TT+TG & 123 & $155(0.467)$ & & 0.748 & 0.108 \\
Recessive & TT & 19 & 22 & 0.748 & & $(0.457-1.622)$ \\
& GG+TG & 311 & 310 & & \\
\hline
\end{tabular}

Note: $\alpha=0.05 / 4=0.0125$.

Abbreviations: $\mathrm{OR}$, odds ratio; $\mathrm{Cl}$, confidence interval; $\mathrm{NA}$, not available.

research on $S N A P 25$, HNMT, FCHSD1, and DBH in northern China is lacking. Studies have shown that these four genes may be involved in PD pathogenesis. ${ }^{8,10,11,13}$ To assess the genetic background related to $\mathrm{PD}$ more comprehensively, we conducted genotype analyses and correlation studies on the newly discovered SNPs of the four genes to accumulate genetic information on PD in a Chinese population. 
SNAP25 is located on chromosome 20p12.2. It encodes a $25-\mathrm{kDa}$ presynaptic plasma-membrane protein involved in the regulation of neurotransmitter release. SNAP25 has been found to be associated with neuropsychiatric and neurological disorders such as autism and Alzheimer's disease. ${ }^{20}$ Agliardi et al investigated five SNPs (rs363050, rs363039, rs363043, rs3746544, and rs1051312) on SNAP25 to analyze a possible correlation with PD. They found that the interaction of these five SNPs had an effect on reducing the PD risk in a case-control study in Italy (2019). We discovered that genotypic and allelic frequencies on the rs 3746544 locus were not significantly different between the PD group and $\mathrm{HC}$ group.

$H N M T$ is located on chromosome $2 \mathrm{q} 22.1$ and is responsible for encoding HNMT. Histamine is a smallmolecule neurotransmitter synthesized from histidine by decarboxylase and degraded by HNMT. Studies have shown that histamine infusion can induce the death of brain neurons in rats, whereas HNMT can inactivate histamine in the brain. ${ }^{21}$ The SNP rs11558538 of HNMT is also known as Thr105Ile, which denotes a rs11558538 C > $\mathrm{T}$ mutation. The association of this SNP with PD is controversial. Keeling et al suggested that the Thr105Ile variant was not a factor in PD progression in North American Caucasians. ${ }^{22}$ However, in a study of populations in the USA and Europe, Palada et al suggested a lower frequency of the rs11558538 C allele in a PD group. ${ }^{10}$ Based on genotypic and allele frequencies on the rs11558538 locus, we found no significant differences between PD patients and $\mathrm{HCs}$ in a northern Chinese population after correction of the genotyping results.

FCHSD1 is located on chromosome 5q31.3. It is a member of a gene group involved in the synthesis of a protein from the mechanistic target of rapamycin kinase (mTOR) signaling pathway. How the mTOR signaling pathway affects PD is not known, but accumulating evidence suggests that the mTOR signaling pathway plays a significant part in the growth, death, survival, metabolism, and proliferation of cells. ${ }^{23,24}$ In recent years, studies have suggested that dysregulation of the mTOR signaling pathway is involved in PD. ${ }^{25,26}$ However, whether the mTOR signaling pathway has a protective role or toxic effect in PD is controversial. Fernandez-Santiago et al suggested that genetic linkage of the loci of SKT11 rs8111699, FCHSD1 rs456998, GSK3B rs 1732170, and SNCA rs356219 was significantly associated with an increased risk of $P D$ in a Spanish population. ${ }^{11}$ However, in other research, overexpression of wild-type mTOR has been shown to protect neurons from damage. ${ }^{25-27}$ Intriguingly, in the present study, distributions of genotypic and allelic frequencies on the FCHSD1 rs456998 locus were significantly different between the PD group and $\mathrm{HC}$ group, data that are consistent with results from PDGene $(P<0.05)$ (www.pdgene.org). However, the four genetic models we created were not significantly different after application of the Bonferroni correction. Our results suggested that the minor allele T of rs 456998 might have a protective role in PD. However, the influence of the power value after statistical analyses suggests that more association studies are needed to verify our results.

$D B H$ is located on chromosome $9 \mathrm{q} 34.2$ and encodes a $69.065-\mathrm{kDa}$ DBH protein. DBH is an enzyme that converts DA to NE in catecholaminergic neurons. ${ }^{13,28,29} \mathrm{DBH}$ regulates DA storage in synaptic vesicles, thereby maintaining the DA:NE ratio in vesicles for appropriate synaptic transmission. ${ }^{30}$ Thus, an abnormality in $D B H$ may be related to susceptibility to PD. Several SNPs that may be related to PD have been reported: $\operatorname{rs} 1611115(-1021 \mathrm{~T}>\mathrm{C})$, rs2283123, rs2007153, rs1611131, rs129882, rs1108580, rs732833, and rs5302. ${ }^{13,31-34}$ An investigation in an east Indian population by Ghosh et al found that the rs 129882 T allele of $D B H$ was more frequent in the case group than that in the control group. However, this genetic locus did not show differences in genotypic and allelic frequencies between the PD group and HC group in the present study.

\section{Conclusions}

Our results indicated that rs456998 might be related to PD. However, the other three SNPs tested did not show an obvious association. Beyond enriching the genetic profile associated with PD in a northern Chinese population, our results suggest that, with the help of GWAS, more candidate loci can be researched in PD, and that this is a valuable research direction.

\section{Acknowledgments}

We are grateful to all previous teammates who had prepared the samples of both PD and control groups.

\section{Author Contributions}

All authors made substantial contributions to conception and design, acquisition of data, or analysis and interpretation of data; took part in drafting the article or revising it critically for important intellectual content; agreed to submit to the current journal; gave final approval of the version to be published; and agree to be accountable for all aspects of the work. 


\section{Disclosure}

The authors have declared that no competing interests exist.

\section{References}

1. Huertas I, Jesus S, Garcia-Gomez FJ, et al. Genetic factors influencing frontostriatal dysfunction and the development of dementia in Parkinson's disease. PLoS One. 2017;12(4):e175560. doi:10.1371/ journal.pone.0175560

2. Abbas MM, Xu Z, Tan LC. Epidemiology of Parkinson's diseaseEast versus West. Mov Disord Clin Pract. 2018;5:14-28. doi:10.1002/mdc3.12568

3. Bellou V, Belbasis L, Tzoulaki I, Evangelou E, Ioannidis JP. Environmental risk factors and Parkinson's disease: an umbrella review of meta-analyses. Parkinsonism Relat Disord. 2016;23:1-9. doi:10.1016/j.parkreldis.2015.12.008

4. Shamoto-Nagai M, Hisaka S, Naoi M, Maruyama W. Modification of alpha-synuclein by lipid peroxidation products derived from polyunsaturated fatty acids promotes toxic oligomerization: its relevance to Parkinson disease. J Clin Biochem Nutr. 2018;62(3):207-212. doi:10.3164/jcbn.18-25

5. Bose A, Beal MF. Mitochondrial dysfunction in Parkinson's disease. J Neurochem. 2016;139(Suppl 1):216-231. doi:10.1111/jnc.13731

6. Lesly Puspita SYCJ. Oxidative stress and cellular pathologies in Parkinson's disease. Mol Brain. 2017;10-53. doi:10.1186/s13041017-0290-2

7. Kalia LV, Lang AE. Parkinson's disease. Lancet. 2015;386 (9996):896-912. doi:10.1016/S0140-6736(14)61393-3

8. Agliardi C, Guerini FR, Zanzottera M, et al. SNAP25 gene polymorphisms protect against Parkinson's disease and modulate disease severity in patients. Mol Neurobiol. 2019;56(6):4455-4463. doi:10.1007/s12035-018-1386-0

9. Haas L, Sergeeva OASO, Selbach O. Histamine in the nervous system. Physiol Rev. 2008;88(3):1183-1241. doi:10.1152/ physrev.00043.2007

10. Palada V, Terzic J, Mazzulli J, et al. Histamine N-methyltransferase Thr105Ile polymorphism is associated with Parkinson's disease. Neurobiol Aging. 2012;33(4):831-836. doi:10.1016/j. neurobiolaging.2011.06.015

11. Fernandez-Santiago R, Martin-Flores N, Antonelli F, et al. SNCA and mTOR pathway single nucleotide polymorphisms interact to modulate the age at onset of Parkinson's disease. Mov Disord. 2019;34 (9):1333-1344. doi:10.1002/mds. 27770

12. DeStefano AL, Golbe LI, Mark MH, et al. Genome-wide scan for Parkinson's disease: the GenePD Study. Neurology. 2001;57 (6):1124-1126. doi:10.1212/WNL.57.6.1124

13. Ghosh A, Sadhukhan T, Giri S, et al. Dopamine beta Hydroxylase $(\mathrm{DBH})$ is a potential modifier gene associated with Parkinson's disease in Eastern India. Neurosci Lett. 2019;706:75-80. doi:10.1016/j. neulet.2019.05.015

14. Chu Q, Luo X, Zhan X, Ren Y, Pang H. Female genetic distribution bias in mitochondrial genome observed in Parkinson's disease patients in northern China. Sci Rep. 2015;5:17170. doi:10.1038/ srep 17170

15. Zhu W, Luo X, Adnan A, et al. Association analysis of NUCKS1 and INPP5K polymorphism with Parkinson's disease. Genes Genet Syst. 2018;93(2):59-64. doi:10.1266/ggs.17-00038

16. Jing CC, Luo XG, Cui HG, et al. Screening of polymorphisms located in the FGF20 and TMEM175 genes in North Chinese Parkinson's disease patients. Genet Mol Res. 2015;14 (4):13679-13687. doi:10.4238/2015.October.28.30

17. Huo Z, Luo X, Zhan X, et al. Genetic analysis of indel markers in three loci associated with Parkinson's disease. PLoS One. 2017;12(9): e184269. doi:10.1371/journal.pone.0184269
18. Hughes AJ, Daniel SE, Kilford L, Lees AJ. Accuracy of clinical diagnosis of idiopathic Parkinson's disease: a clinico-pathological study of 100 cases. J Neurol Neurosurg Psychiatry. 1992;55 (3):181-184. doi:10.1136/jnnp.55.3.181

19. Reich SG, Savitt JM. Parkinson's disease. Med Clin North Am. 2019;103(2):337-350. doi:10.1016/j.mcna.2018.10.014

20. Guerini FR, Bolognesi E, Chiappedi M, et al. SNAP-25 single nucleotide polymorphisms are associated with hyperactivity in autism spectrum disorders. Pharmacol Res. 2011;64(3):283-288. doi:10.1016/j.phrs.2011.03.015

21. Vizuete ML, Merino M, Venero JL, Santiago M, Cano J, Machado A. Histamine infusion induces a selective dopaminergic neuronal death along with an inflammatory reaction in rat substantia nigra. $J \quad$ Neurochem. 2000;75(2):540-552. doi:10.1046/j.14714159.2000.0750540.x

22. Keeling BH, Vilarino-Guell C, Soto-Ortolaza AI, et al. Histamine $\mathrm{N}$-methyltransferase Thr105Ile is not associated with Parkinson's disease or essential tremor. Parkinsonism Relat Disord. 2010;16 (2):112-114. doi:10.1016/j.parkreldis.2009.08.011

23. Laplante M, Sabatini DM. mTOR signaling in growth control and disease. Cell. 2012;149(2):274-293. doi:10.1016/j.cell.2012.03.017

24. Cornu M, Albert V, Hall MN. mTOR in aging, metabolism, and cancer. Curr Opin Genet Dev. 2013;23(1):53-62. doi:10.1016/j. gde.2012.12.005

25. Zhou Q, Liu C, Liu W, et al. Rotenone induction of hydrogen peroxide inhibits mTOR-mediated S6K1 and 4E-BP1/eIF4E pathways, leading to neuronal apoptosis. Toxicol Sci. 2015;143 (1):81-96. doi:10.1093/toxsci/kfu211

26. Xu Y, Liu C, Chen S, et al. Activation of AMPK and inactivation of Akt result in suppression of mTOR-mediated S6K1 and 4E-BP1 pathways leading to neuronal cell death in in vitro models of Parkinson's disease. Cell Signal. 2014;26(8):1680-1689. doi:10.1016/j.cellsig.2014.04.009

27. Malagelada C, Jin ZH, Jackson-Lewis V, Przedborski S, Greene LA. Rapamycin protects against neuron death in in vitro and in vivo models of Parkinson's disease. J Neurosci. 2010;30(3):1166-1175. doi:10.1523/JNEUROSCI.3944-09.2010

28. Kim CH, Leung A, Huh $\mathrm{YH}$, et al. Norepinephrine deficiency is caused by combined abnormal mRNA processing and defective protein trafficking of dopamine beta-hydroxylase. $J$ Biol Chem. 2011;286(11):9196-9204. doi:10.1074/jbc.M110.192351

29. Kim CH, Zabetian CP, Cubells JF, et al. Mutations in the dopamine beta-hydroxylase gene are associated with human norepinephrine deficiency. Am J Med Genet. 2002;108(2):140-147. doi:10.1002/ ajmg. 10196

30. Cubells JF, Zabetian CP. Human genetics of plasma dopamine beta-hydroxylase activity: applications to research in psychiatry and neurology. Psychopharmacology (Berl). 2004;174(4):463-476. doi:10.1007/s00213-004-1840-8

31. Punia S, Das M, Behari M, et al. Role of polymorphisms in dopamine synthesis and metabolism genes and association of $\mathrm{DBH}$ haplotypes with Parkinson's disease among North Indians. Pharmacogenet Genomics. 2010;20(7):435-441. doi:10.1097/ FPC.0b013e32833ad3bb

32. Chun LS, Samii A, Hutter CM, et al. DBH $-1021 \mathrm{C}->\mathrm{T}$ does not modify risk or age at onset in Parkinson's disease. Ann Neurol. 2007;62(1):99-101. doi:10.1002/ana.21149

33. Tang S, Yao B, Li N, Lin S, Huang Z. Association of dopamine betahydroxylase polymorphisms with Alzheimer's disease, Parkinson's disease and schizophrenia: evidence based on currently available loci. Cell Physiol Biochem. 2018;51(1):411-428. doi:10.1159/000495238

34. Healy DG, Abou-Sleiman PM, Ozawa T, et al. A functional polymorphism regulating dopamine beta-hydroxylase influences against Parkinson's disease. Ann Neurol. 2004;55(3):443-446. doi:10.1002/ ana.20063 


\section{Publish your work in this journal}

Neuropsychiatric Disease and Treatment is an international, peerreviewed journal of clinical therapeutics and pharmacology focusing on concise rapid reporting of clinical or pre-clinical studies on a range of neuropsychiatric and neurological disorders. This journal is indexed on PubMed Central, the 'PsycINFO' database and CAS, and is the official journal of The International Neuropsychiatric Association (INA). The manuscript management system is completely online and includes a very quick and fair peer-review system, which is all easy to use. Visit http://www.dovepress.com/testimonials.php to read real quotes from published authors.

Submit your manuscript here: https://www.dovepress.com/neuropsychiatric-disease-and-treatment-journal 